\title{
Diversidade genética entre e dentro de populações de Cenostigma tocantinum Ducke
}

\author{
Genetic diversity among and within populations \\ of Cenostigma tocantinum Ducke
}

Fabíola Viana de Almeida1, Maria Teresa Gomes Lopes², Mágno Sávio Ferreira Valente ${ }^{3}$ e Jania Lilia da Silva Bentes ${ }^{2}$

\begin{abstract}
Resumo
Cenostigma tocantinum Ducke é uma espécie arbórea, arbustiva, nativa do Brasil. Sua madeira é utilizada na construção civil e a árvore em projetos de arborização. Este estudo objetivou avaliar a diversidade genética entre e dentro de populações de $C$. tocantinum usadas em projetos de arborização urbana, por meio de marcadores AFLP. Foram amostradas 90 plantas em três populações de cidades do estado do Amazonas: Manaus, Parintins e Presidente Figueiredo. Os marcadores AFLP foram eficientes na diferenciação genética das populações, revelando 186 locos, $132(71 \%)$ polimórficos, a partir de quatro combinações de oligonucleotídeos. O teste de Mantel indicou que a distância geográfica está correlacionada com a divergência genética entre as populações ( $r: 0,5034 ; P=0,001$ ), o que pode ter sido influenciado pelo fluxo gênico observado. O dendrograma e a análise bayesiana de agrupamento permitiram a identificação de maior similaridade genética entre as populações de Manaus e Parintins. Contudo, a maior parte da diversidade genética ocorre dentro das populações. As variações inter e intrapopulacionais foram de $36,6 \%$ e $63,4 \%$, respectivamente. Para espécies arbóreas, como C. tocantinum, usadas em projetos de arborização urbana, a introdução de plantas em novos projetos, oriundas de amostragem adequada em outras populações, auxilia na conservação genética da espécie.
\end{abstract}

Palavras-chave: Cenostigma tocantinum, variabilidade genética, AFLP.

\begin{abstract}
C. tocantinum (Caesalpinoideae) is an arboreal and shrubby species, native to Brazil and its wood is used in building and the trees are used in afforestation projects. This study aimed to evaluate genetic diversity among and within $C$. tocantinum populations used in afforestation projects by AFLP markers. Ninety plants were sampled in three populations in cities of the state of Amazonas: Manaus, Parintins and Presidente Figueiredo. The AFLP markers were efficient for the genetic differentiation of populations, revealing 186 loci, $132(71 \%)$ being polymorphic, from four combinations of primers. The mantel test indicated that geographical distance is correlated with the genetic differentiation among populations $(\mathrm{r}: 0.5034, \mathrm{P}$ $=0.001$ ), which may have been influenced by gene flow. The clustering and Bayesian cluster analysis permitted the identification of genetic similarity between the populations of Manaus and Parintins. However, most genetic diversity occurs within populations. The inter- and intra-population variations were $36.6 \%$ and $63.4 \%$, respectively. For an arboreal species, such as C. tocantinum, used in urban afforestation projects, the introduction of plants into news projects coming from appropriate sampling in other populations assists in the genetic conservation of the species.
\end{abstract}

Keywords: Cenostigma tocantinum, genetic variability, AFLP.

\section{INTRODUÇÃO}

Cenostigma tocantinum Ducke é uma espécie nativa da Amazônia utilizada na arborização urbana devido à beleza de sua floração e de aspectos favoráveis como tronco reto, crescimento rápido, copa frondosa, que proporciona sombreamento eficiente e sem a liberação de grande quantidade

\footnotetext{
${ }^{1}$ Mestranda do Programa de Pós-Graduação de Ciências Florestais e Ambientais da Faculdade de Ciências Agrárias. UFAM - Universidade Federal do Amazonas. Av. General Rodrigo Otávio, 6.200 - Coroado - 69077-000 - Manaus, AM. E-mail: fabiol.a.lmeida@hotmail.com.

${ }^{2}$ Professora Doutora da Faculdade de Ciências Agrárias. UFAM - Universidade Federal do Amazonas. Av. General Rodrigo Otávio, 6.200 - Coroado - 69077-000 - Manaus, AM. E-mail: mtglopes@hotmail.com; jlbentes@ufam.edu.br

3Pesquisador Doutor da Faculdade de Ciências Agrárias. UFAM - Universidade Federal do Amazonas - Av. General Rodrigo Otávio, 6.200 - Coroado - 69077-000 - Manaus, AM - E-mail: magnosavio@yahoo.com.br
} 
de folhas, bem como sistema radicular pouco agressivo (GARCIA et al., 2008). A espécie também apresenta baixa suscetibilidade ao ataque de pragas e doenças, o que a tem tornado atrativa para o plantio na arborização urbana, pois o processo de fragmentação florestal isola e reduz o tamanho das populações florestais tornando-as significativamente mais vulneráveis a eventos ambientais, demográficos e ou genéticos (BATISTA et al., 2012).

É importante conhecer a diversidade genética de populações de C. tocantinum presentes em áreas urbanas, pois muitas vezes estas se tornam matrizes alvo de coleta de sementes para uso em outros projetos de arborização e para o plantio realizado pelos próprios moradores locais. A coleta realizada em poucos genótipos ou em genótipos aparentados pode facilitar a redução da base genética das populações e ao favorecer a maior diversidade de genótipos em plantios é evitada a vulnerabilidade genética a doenças, a pragas e a condições edafo-climáticas adversas (LINS et al., 2003).

A caracterização da diversidade genética pode ser realizada por meio de marcadores moleculares, sendo fundamentais na análise das diferenças nos perfis genéticos e na identificação de alelos específicos nas populações em estudo. Atualmente existe uma grande variedade de marcadores moleculares disponíveis na literatura, que permitem detectar polimorfismo em espécies florestais $\mathrm{e}$, portanto, permitem analisar a variabilidade genética entre e dentro de populações. Entre esses marcadores, destaca-se o Polimorfismo de Comprimento de Fragmentos Amplificados (AFLP) que não requer uso de sondas ou bibliotecas genômicas e pode ser usado para qualquer espécie que não possua informações genéticas prévias (BONIN et al., 2007; VUYLSTEKE et al., 2007), a exemplo de C. tocantinum.

Embora os aspectos florais, de frutos e de sementes em C. tocantinum venham recebendo interesse da comunidade científica (SILVA, 2007; WARWICK; LEWIS, 2009), ainda não se tem informações relevantes na literatura sobre a diversidade genética em populações naturais da espécie. No Brasil, e em especial na região norte, há uma carência sobre estudos de diversidade genética em espécies nativas e exóticas, sobretudo em ambientes urbanos. Diante da grande diversidade de espécies arbóreas nativas presente na região e a crescente exploração predatória nas florestas tropicais, é importante que fatores que afetem a estrutura genética dessas populações sejam identificados e que estratégias de conservação sejam estabelecidas a fim de conservar um maior número de plantas e animais.

Conhecer a diversidade genética de populações de uma espécie é um passo importante para recomendação quanto à constituição de lotes de sementes para os plantios, para a conservação e o melhoramento genético. Deste modo, o presente trabalho objetivou avaliar a diversidade genética entre e dentro de populações de C. tocantinum presentes em municípios do Estado do Amazonas, com auxílio de marcadores moleculares AFLP.

\section{MATERIAL E MÉTODOS}

Foram estudadas populações de C. tocantinum utilizadas em arborização urbana em três cidades do Estado do Amazonas: Manaus ( $3^{\circ} 6^{\prime} \mathrm{S}$ e $60^{\circ} 1^{\prime} \mathrm{W}$ ), Parintins $\left(2^{\circ} 37^{\prime} \mathrm{S}\right.$ e $56^{\circ} 44^{\prime} \mathrm{W}$ ) e Presidente Figueiredo $\left(2^{\circ} 2^{\prime} \mathrm{S}\right.$ e $\left.60^{\circ} 1^{\prime} \mathrm{W}\right)$. As árvores da espécie quando usadas na arborização urbana originam-se do plantio de mudas provenientes de sementes. Cada população foi constituída de uma amostra de 30 plantas, totalizando 90 plantas no estudo, sendo todas devidamente identificadas e suas posições geográficas registradas com sistema de posicionamento global - GPS.

Foram amostradas árvores localizadas em ruas e praças de área urbana. Folhas jovens e sadias foram colhidas de cada planta, acondicionadas em sacos plásticos, devidamente identificados, contendo sílica gel e armazenadas à temperatura de $-20{ }^{\circ} \mathrm{C}$ para posterior extração do DNA e análise com marcadores AFLP no Laboratório de Melhoramento Genético Vegetal (LAB-MGV) da Faculdade de Ciências Agrárias da UFAM. Em testes preliminares, a extração do DNA foi feita em folhas submetidas a diferentes tempos de armazenamento a fim de verificar a influência deste fator na qualidade dos pellets obtidos.

O DNA genômico foi extraído de acordo com o protocolo CTAB descrito por Ferreira e Grattapaglia (1998) com algumas modificações. Estas incluíram a retirada da proteinase K ao tampão de extração; a extração com CIA foi feita apenas uma vez; e foi retirada a etapa de limpeza com $\mathrm{NaCl}$ para a extração com folhas frescas. Para cada amostra, macerou-se aproximadamente $60 \mathrm{mg}$ de tecido foliar fresco sem a nervura principal. 
A análise de marcadores AFLP foi realizada segundo os procedimentos propostos por Vos et al. (1995), com modificações de Lopes et al. (2003). Para as reações de digestão do DNA, foi utilizada a combinação de enzimas de restrição EcoRI/MseI. Foi utilizado 200 ng de DNA genômico, 5,0 $\mu \mathrm{L}$ do tampão One Phor All-OPA 10X (Pharmacia), 0,5 $\mu \mathrm{L}$ de solução Albumina de Soro Bovino-BSA

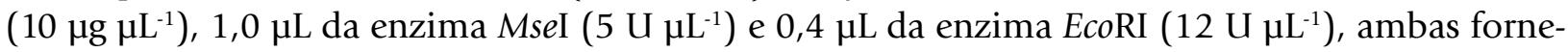
cidas pelo New England Biolabs, em volume final de $50 \mu \mathrm{L}$. O material foi incubado em termociclador ESCO ${ }^{\circledast}$ PCR Thermal Ciclers por três horas a $37^{\circ} \mathrm{C}$ para as reações de restrição e, em seguida, por 15 minutos a $70{ }^{\circ} \mathrm{C}$ para inativação das endonucleases.

Foram preparados adaptadores específicos de EcoRI e MseI que possuem terminais complementares às extremidades resultantes da digestão pelas enzimas de restrição. O adaptador EcoRI foi preparado utilizando 5,6 $\mu \mathrm{L}$ de adaptador EcoRI forward, 4,8 $\mu \mathrm{L}$ de adaptador EcoRI reverse, $6 \mu \mathrm{L}$ de tampão OPA (Amersham ${ }^{\circledast}$ e água ultrapura esterilizada para o volume final de $120 \mu \mathrm{L}$. O adaptador MseI foi preparado utilizando $64 \mu \mathrm{L}$ de adaptador MseI forward, $56 \mu \mathrm{L}$ de adaptador MseI reverse, $7 \mu \mathrm{L}$ de tampão OPA (Amersham ${ }^{\circledR}$ e água ultrapura esterilizada para o volume final de $140 \mu \mathrm{L}$. Ambos os adaptadores foram incubados no termociclador ESCO ${ }^{\circledast}$ PCR Thermal Ciclers em temperaturas subsecutivas de 65,37 e $25^{\circ} \mathrm{C}$, com duração de dez minutos cada. Para a reação de ligação dos adaptadores foi utilizado 1,0 $\mu \mathrm{L}$ de adaptador EcoRI, 1,0 $\mu \mathrm{L}$ de adaptador MseI, 1,0 $\mu \mathrm{L}$ de tampão para a enzima T4 DNA Ligase (10X), 0,33 $\mu \mathrm{L}$ da enzima T4 DNA Ligase ( $3 \mathrm{U} / \mu \mathrm{L}$ ) (Promega ${ }^{\circledR}$ e água ultrapura esterilizada completando o volume para $10 \mu \mathrm{L}$. Este mix foi adicionado a $50 \mu \mathrm{L}$ do DNA digerido com as enzimas de restrição. As amostras foram incubadas em termociclador a 23 ${ }^{\circ} \mathrm{C}$ por 3 horas e estocadas a $-20^{\circ} \mathrm{C}$. Foram utilizados $0,6 \mu \mathrm{L}$ de $\mathrm{MgCl}_{2}(25 \mathrm{mM}), 0,4 \mu \mathrm{L}$ de dNTPs $(10 \mathrm{mM}), 0,5 \mu \mathrm{L}$ de cada oligonucleotídeo contendo um nucleotídeo seletivo adicionado à extremidade 3': oligo EcoRI $(25 \mathrm{ng} / \mu \mathrm{L})+$ A e oligo Mse I $(25 \mathrm{ng} / \mu \mathrm{L})+\mathrm{C}, 1,0 \mu \mathrm{L}$ de tampão da enzima Taq DNA polimerase (10X) (Fermentas $\left.{ }^{\circledast}\right), 0,3 \mu \mathrm{L}$ de Taq DNA polimerase $(5 \mathrm{U} / \mu \mathrm{L})\left(\right.$ Fermentas $\left.{ }^{\circledast}\right), 2,5$ $\mu \mathrm{L}$ de DNA digerido e ligado, e água ultrapura para completar o volume para $10 \mu \mathrm{L}$. As amostras foram incubadas em termociclador a $94{ }^{\circ} \mathrm{C}$ por dois minutos, seguidos de 26 ciclos de 94,56 e 72 ${ }^{\circ} \mathrm{C}$, com duração de um minuto para cada temperatura, e uma extensão final de $72{ }^{\circ} \mathrm{C}$ por cinco minutos. Terminada a reação de PCR foram acrescentados $40 \mu \mathrm{L}$ de água ultrapura a cada amostra, as quais foram armazenadas a $-20^{\circ} \mathrm{C}$. As sequências dos oligonucleotídeos usados na reação de pré-amplificação foram E+AGT/M+CAT, E+AGT/M+CAC, E+AGT/M+CCA, E+AGT/M+CTC, E+AGC/ $\mathrm{M}+\mathrm{CAT}, \mathrm{E}+\mathrm{AGC} / \mathrm{M}+\mathrm{CAC}, \mathrm{E}+\mathrm{AGC} / \mathrm{M}+\mathrm{CCA}, \mathrm{E}+\mathrm{AGC} / \mathrm{M}+\mathrm{CTC}$. Para as reações de amplificação seletiva foram utilizados $1,2 \mu \mathrm{L}$ de $\mathrm{MgCl}_{2}(25 \mathrm{mM}), 0,4 \mu \mathrm{L}$ de dNTPs $(10 \mathrm{mM}), 1,0 \mu \mathrm{L}$ do oligo EcoRI (25 $\mathrm{ng} / \mu \mathrm{L})+\mathrm{ANN}, 1,2 \mu \mathrm{L}$ do oligo Mse $(25 \mathrm{ng} / \mu \mathrm{L})+\mathrm{CNN}$ (Em que N é o nucleotídeo arbitrário usado na amplificação seletiva), 2,0 $\mu \mathrm{L}$ de tampão da enzima Taq DNA polimerase (10X) (Fermentas ${ }^{\circledR}$ ), 0,2 de Taq DNA polimerase $(5 \mathrm{U} / \mu \mathrm{L})$ (Fermentas $\left.{ }^{\circledR}\right), 1,5 \mu \mathrm{L}$ de DNA das amostras pré-amplificadas, e água ultrapura para completar o volume de $20 \mu \mathrm{L}$. As amostras foram incubadas em termociclador à temperatura $94{ }^{\circ} \mathrm{C}$ por dois minutos, seguida de 12 ciclos de 94,65 e $72{ }^{\circ} \mathrm{C}$ com duração de 30, 30 e 60 segundos, respectivamente, mais 23 ciclos de 94,56 e $72{ }^{\circ} \mathrm{C}$ com duração de 30, 30 e 60 segundos, respectivamente, e uma extensão final de $72{ }^{\circ} \mathrm{C}$ por dois minutos. As amostras foram estocadas a $-20^{\circ} \mathrm{C}$. Posteriormente, as amostras foram submetidas à eletroforese em gel de poliacrilamida $6 \%$ (acrilamida/bis-acrilamida (19:1 v/v)). Às amostras foram adidos $8 \mu \mathrm{L}$ de loading buffer

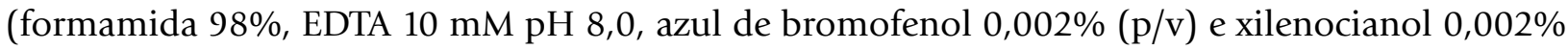
$(\mathrm{p} / \mathrm{v}))$ as quais foram incubadas no termociclador por cinco minutos à temperatura de $95{ }^{\circ} \mathrm{C}$ para desnaturação. Em seguida, foram aplicados $20 \mu \mathrm{L}$ da amostra desnaturada no gel para eletroforese sob potência constante de $80 \mathrm{~W}$ durante três horas. Para a revelação do gel, usou-se o método de coloração com nitrato de prata segundo o protocolo proposto por Creste et al. (2001).

A partir da leitura cuidadosa dos géis de poliacrilamida, foi construída uma matriz binária em que zero e um indicaram ausência e presença de fragmentos, respectivamente. Os dados obtidos foram usados na construção de uma matriz de distâncias genéticas com base na distância genética corrigida de Nei (NEI, 1978). Para visualização da diferenciação genética entre as populações de C. tocantinum, foram construídos dendrogramas por análise de agrupamentos do tipo UPGMA (Unweighted Pair Group Method using Arithmetical Averages) com o auxílio do software estatístico R (R DEVELOPMENT CORE TEAM, 2013). A adequação da análise de agrupamento aos dados originais foi avaliada pelo coeficiente de correlação cofenética proposto por Sokal e Rohlf (1962). 
Posteriormente, foi aplicada análise de escalonamento multidimensional não métrico (NMDS), em que a maior dispersão das unidades foi identificada como havendo maior dissimilaridade genética. Para a obtenção das análises foi utilizado o pacote vegan (OKSANEN et al., 2013) do software R. O procedimento partiu de uma organização inicial que, interativamente, reorganizou os indivíduos de maneira a diminuir o stress (STandard REsiduals Sum of Squares). O stress (S) é uma função que informa a magnitude da perda de informação na matriz de similaridade com a utilização do procedimento, sendo esta uma medida do quanto às posições dos indivíduos em uma configuração n-dimensional desviam-se das reais distâncias (similaridades) após o escalonamento. O stress foi interpretado pelo valor de $\mathrm{R}^{2}=1-\mathrm{S}^{2}$.

Pelo pressuposto de que as populações estão em equilíbrio de Hardy-Weinberg, o programa Popgene versão 1.32 (YEH et al., 1999) foi usado para o cálculo da variação genética em cada população. As estimativas de diversidade intrapopulacional incluíram a heterozigosidade esperada, $\mathrm{H}_{e}(\mathrm{NEI}$, 1978) e o índice de diversidade genética de Shannon e Weaver, I (SHANNON; WEAVER, 1949). Em análise adicional, foi estimado o valor de fluxo gênico entre as populações. Para investigar a correlação entre a distância geográfica e a diversidade genética das populações foi utilizado o teste de Mantel (MANTEL, 1967), a partir do software estatístico R com 999 permutações. A abordagem bayesiana implementada no software Structure v.2.4 (PRITCHARD et al., 2000, FALUSH et al., 2003) foi utilizada para revelar a estrutura das populações. O número de interações utilizadas no burn-in e MCMC (Markov Chain Monte Carlo) foram de 100.000 e 200.000, respectivamente. Nas análises, foi considerado o modelo de mistura com frequências correlacionadas com a incorporação $a$ priori das informações sobre locais de amostragem. Foram testados valores de agrupamento $(\mathrm{K})$ variando de 1 a 5 com cinco repetições idênticas para cada valor de $\mathrm{K}$ testado. O valor mais provável de K foi determinado pelo critério DK descrito por Evanno et al. (2005) a partir do programa Structure Harvester (EARL; VONHOLDT, 2011). A visualização gráfica da estrutura populacional se deu através do software Distruct (ROSENBERG, 2003), usando a repetição que proporcionasse o maior valor do logaritmo da função de verossimilhança. A distribuição da variação genética entre e dentro das populações foi quantificada pela análise da variância molecular (AMOVA), realizada pelo programa GenALEX v.6.5 (PEAKALL; SMOUSE, 2012).

\section{RESULTADOS E DISCUSSÃO}

As amostras de folhas de C. tocantinum geraram DNA com quantidade e qualidade satisfatórias para análises dos marcadores AFLP. As folhas armazenadas em sacos plásticos contendo sílica gel a $-20{ }^{\circ} \mathrm{C}$ por pelo menos 20 dias apresentaram qualidade de DNA semelhante à extração em folhas frescas. Contudo, a experiência mostra que a utilização de tecido foliar fresco e jovem é o mais indicado (SYSTMA et al., 1993).

Entre as oito combinações de oligonucleotídeos utilizadas, quatro foram selecionadas para a análise de todas as amostras por apresentar maior número de locos polimórficos e melhor qualidade de amplificação das bandas (E+AGT/M+CAT, E+AGT/M+CTC, E+AGT/M+CAC, E+AGT/M+CCA). As combinações de oligonucleotídeos analisadas nas três populações totalizaram 186 locos, sendo $132(71 \%)$ polimórficos. Houve uma variação de 29 a 37 locos polimórficos por combinação de oligonucleotídeo (Tabela 1). O percentual de locos polimórficos encontrados neste trabalho é comparável a outros trabalhos com espécies arbóreas, tanto usando marcadores AFLP (MAGALHÃES et al., 2013) como em marcadores RAPD (AGUIAR et al., 2013).

Tabela 1. Combinações de oligonucleotídeos e quantidade de locos polimórficos.

Table 1. Combinations of primers and number of polymorphic loci.

\begin{tabular}{lccc}
\hline Combinações de oligonucleotídeos & Locos Polimórficos & Locos Monomórficos & Locos Totais \\
E-agt/M-cac & 31 & 12 & 43 \\
E-agt/M-cat & 29 & 9 & 38 \\
E-agt/M-cca & 37 & 16 & 53 \\
E-agt/M-ctc & 35 & 17 & 52 \\
Total & 132 & 54 & 186 \\
\hline
\end{tabular}


Os valores da heterozigosidade esperada $\left(\mathrm{H}_{\mathrm{e}}\right)$ e o índice de diversidade genética de Shannon e Weaver (I) apresentaram baixa variação nas três populações (Tabela 2). A população Presidente Figueiredo apresentou os maiores valores de $\mathrm{H}_{e}(0,284)$ e $I(0,431)$, sugerindo maior diversidade genética intrapopulacional. Estes resultados foram similares ao detectados por Torezan et al. (2005) em Aspidosperma polyneuron, $\left(\mathrm{H}_{\mathrm{e}}=0,28\right.$ e $\mathrm{I}=0,41$, respectivamente) e inferiores aos observados por Estopa et al. (2006) em populações naturais de Eremanthus erythropappus $\left(\mathrm{H}_{\mathrm{e}}\right.$ variando de 0,29 a $0,32 \mathrm{e}$ I de 0,45 a 0,50). No nível de espécie, os dois índices apresentaram valores médios de 0,336 e 0,510, respectivamente. Contudo, ressalta-se que a comparação destes valores com outros estudos deve ser interpretada com cautela, pois abordagens diferentes podem ter sido utilizadas para calculá-los.

Tabela 2. Diversidade genética dentro de populações de Cenostigma tocantinum e em nível de espécie.

Table 2. Genetic diversity within populations of Cenostigma tocantinum and in the species.

\begin{tabular}{lccc}
\hline População & $\mathbf{n}$ & $\mathbf{H}_{\mathrm{e}}$ & $\mathbf{I}$ \\
\hline Manaus & 30 & $0,240( \pm 0,013)$ & $0,383( \pm 0,017)$ \\
Parintins & 30 & $0,264( \pm 0,014)$ & $0,413( \pm 0,018)$ \\
Presidente Figueiredo & 30 & $0,284( \pm 0,016)$ & $0,431( \pm 0,020)$ \\
Espécie & 90 & $0,336( \pm 0,012)$ & $0,510( \pm 0,015)$ \\
\hline
\end{tabular}

$\mathrm{n}$ = tamanho da amostra; $\mathrm{H}_{\mathrm{e}}$ = heterozigosidade esperada; I = índice de diversidade genética de Shannon e Weaver (I949). ( ) Desvio padrão.

A estimativa da distância genética corrigida de Nei produziu dois grupos, o primeiro formado exclusivamente pela população de Presidente Figueiredo e o segundo pelas populações de Manaus e Parintins (Figura 1). A menor e maior distância genética foi entre as populações de Manaus e Parintins $(0,142)$ e Manaus e Presidente Figueiredo $(0,182)$, respectivamente (Tabela 3$)$. Isso indica que as duas primeiras populações são mais similares entre si e sugere maior fluxo gênico entre estas. A estimativa do número de imigrantes por geração ou fluxo gênico histórico médio entre todas as populações foi considerável $(\mathrm{Nm}=1,78)$, variando entre pares de populações de 2,06 a 2,68. Valores de $\mathrm{Nm}>1$ sugerem haver movimento de genes entre populações suficientes para prevenir a diferenciação entre elas devido à deriva genética (SLATKIN; BARTON, 1989). Em concordância, a estatística de Mantel foi significativamente maior do que zero $(r=0,503, P=0,001)$, o que mostra que a distância geográfica está correlacionada com a diferenciação genética entre as populações. Logo, populações localizadas espacialmente próximas são geneticamente mais similares entre si do que as localizadas a maiores distancias. Isso pode ser atribuído ao maior fluxo gênico entre populações próximas, uma vez que a proximidade geográfica implica na maior probabilidade de fluxo gênico (BOSSART; PROWELL, 1998).

Se considerarmos que as populações amostradas retém grande parte da variabilidade da população original, a diversidade genética observada entre as populações possivelmente seja remanescente do período onde as populações não se apresentavam tão fragmentadas. Anteriormente a antropização da região, mesmo que as populações não formassem um contínuo na natureza, elas provavelmente estariam menos distanciadas e com um maior número de indivíduos, mantendo um constante fluxo gênico entre elas.

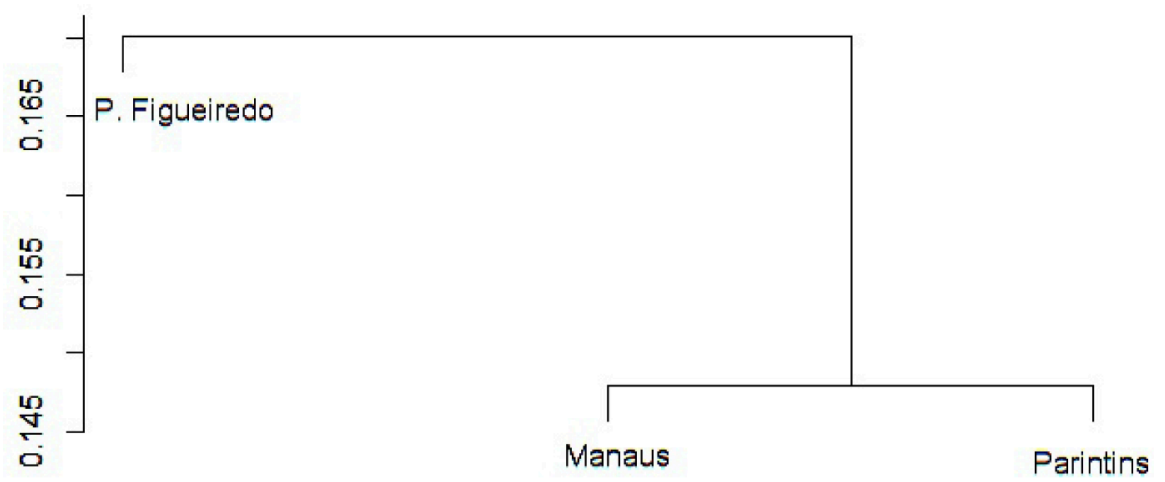

Figura 1. Análise de agrupamento (UPGMA) a partir da distância genética corrigida de Nei (1978), para três populações de Cenostigma tocantinum. Coeficiente de correlação cofenética: $r=0,555$.

Figure 1. Cluster analysis (UPGMA) from the corrected genetic distance as in Nei (1978), for three populations of Cenostigma tocantinum. Cophenetic correlation coefficient: $r=0.555$ 
Almeida et al. - Diversidade genética entre e dentro

de populações de Cenostigma tocantinum Ducke

Tabela 3. Estimativas de fluxo gênico (diagonal superior) e distância genética corrigida de Nei (1978) (diagonal inferior) entre as populações de Cenostigma tocantinum.

Table 3. Estimates of gene flow (upper diagonal) and genetic distance corrected of Nei (1978) (lower diagonal) between populations of Cenostigma tocantinum.

\begin{tabular}{lccc}
\hline População & Manaus & Parintins & Presidente Figueiredo \\
\hline Manaus & - & 2,44 & 2,06 \\
Parintins & 0,142 & - & 2,68 \\
Presidente Figueiredo & 0,182 & 0,145 & - \\
\hline
\end{tabular}

A representação da relação de similaridade entre os acessos a partir de dois eixos foi realizada pelo procedimento NMDS (Figura 2). As distâncias representadas tiveram ajustamento satisfatório em comparação as distâncias genéticas originais $\left(R^{2}=0,974\right)$. É possível observar que alguns acessos de Manaus e, principalmente de Presidente Figueiredo, estão mais distanciados geneticamente do resto da população de origem geográfica, podendo ser entendidos como um novo grupo ou resultado de intercâmbio de material genético entre as localidades. Deste modo, estes acessos estariam posicionados em distância intermediária entre as populações parentais.

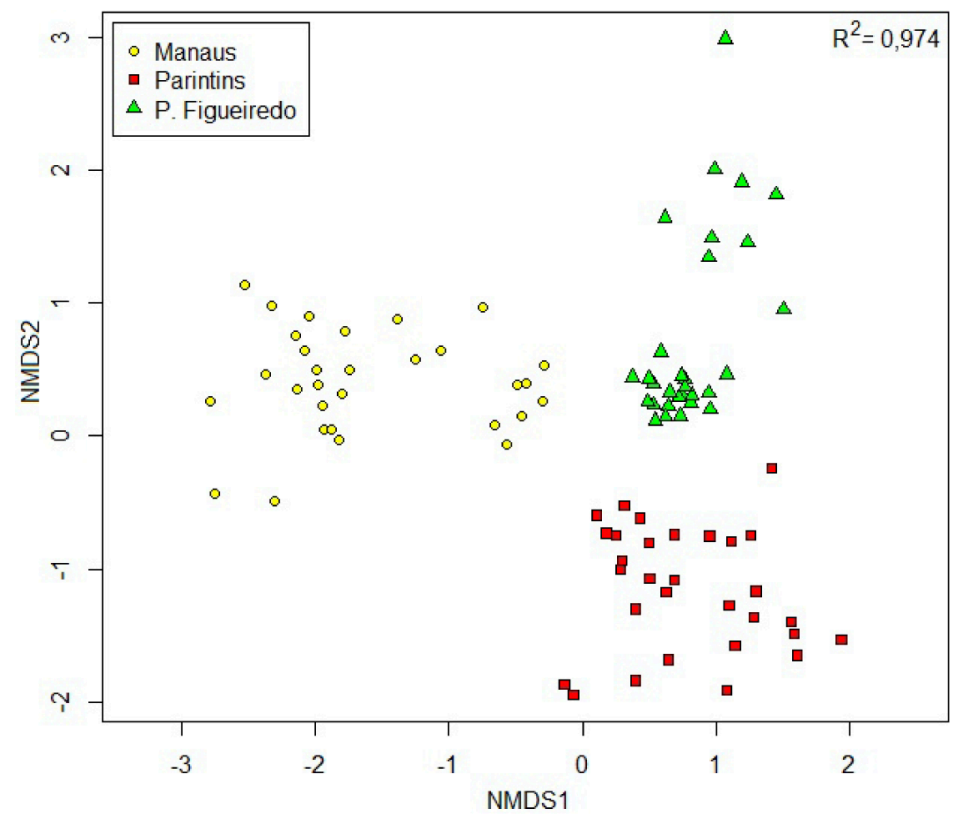

Figura 2. Análise de escalonamento multidimensional não-métrico das distâncias genéticas entre indivíduos de Cenostigma tocantinum.

Figure 2. Analysis of non-metric multidimensional scaling of genetic distances between individuals of Cenostigma tocantinum.

Para determinar os padrões genéticos de diferenciação e subestruturação populacional foi feita a análise Bayesiana pelo software Structure e, de acordo com o método DK descrito por Evanno et al. (2005) e conhecimento prévio da origem geográfica das populações, o número mais provável de agrupamentos foi $\mathrm{K}=3$. A visualização gráfica da estrutura populacional permitiu a separação das três populações em três grupos distintos de acordo com a origem geográfica (Figura 3). Contudo, alguns acessos, principalmente na população de Presidente Figueiredo, apresentaram mistura de material genético dos demais grupos, o que corroboram com os resultados da análise NMDS e indicaria que estes indivíduos podem ter origem compartilhada, sendo resultado de um intercâmbio de genes entre as populações analisadas. A partir da análise de $\mathrm{K}=2$ é possível observar que a população de Presidente Figueiredo é mais divergente das demais, concordando com as análises anteriores. O Structure separa os indivíduos mais discrepantes em populações mais distantes e em seguida, ao aumentar o número de grupos testados, identifica as populações mais similares. Assim, através de um alinhamento crescente dos resultados da análise gráfica de acordo com o K testado, conseguimos ter uma melhor noção da relação entre as populações (VIANA et al., 2013). 


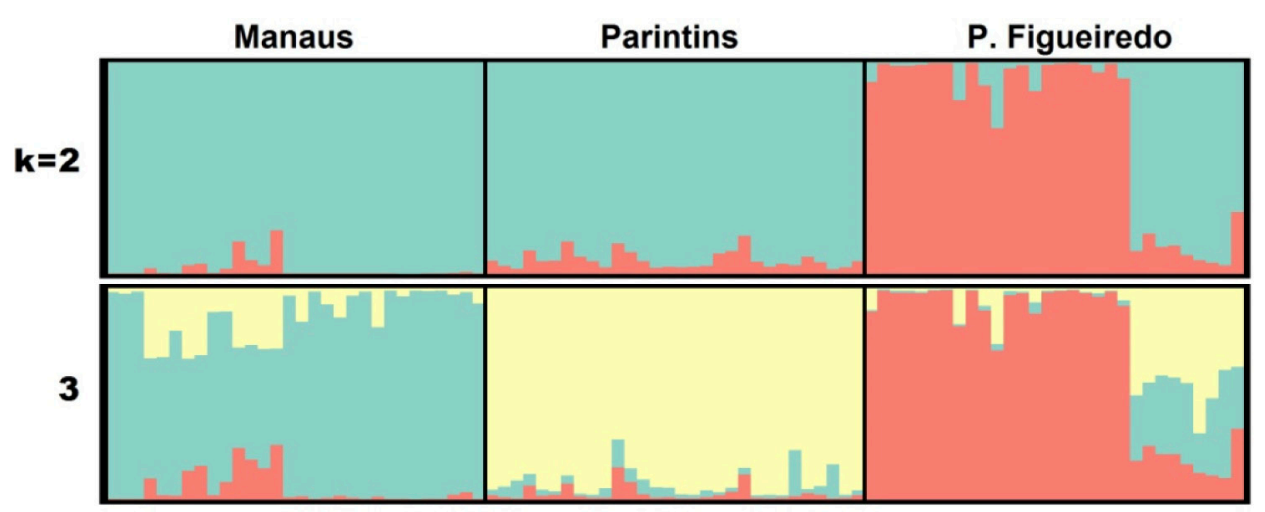

Figura 3. Estrutura populacional empregando o software Structure a partir de 90 indivíduos de Cenostigma tocantinum amostrados das populações de Manaus, Parintins e Presidente Figueiredo para diferentes valores de agrupamentos (K).

Figure 3. Population structure using the software Structure, from 90 individuals of Cenostigma tocantinum sampled of populations of Manaus, Parintins and Presidente Figueiredo for different values of clusters (K).

A estimativa da diferenciação genética $\left(\Phi_{s t}\right)$ entre populações mostrou que $63,4 \%$ da variabilidade genética está distribuída dentro e 36,6\% entre as populações (Tabela 4). Os resultados encontrados estão de acordo aos apresentados na literatura para populações naturais de espécies arbóreas tropicais que mostram que, em geral, a maior parte da diversidade genética encontra-se dentro das populações (GOMES et al., 2011; ROSSI et al, 2014). No entanto, deve-se considerar que as populações estudadas não são naturais, são populações plantadas para a arborização urbana. Foram obtidas informações junto aos moradores sobre a origem das mudas das plantas utilizadas na arborização. Constatou-se que as sementes são provenientes de locais próximos à cidade, principalmente de árvores de populações naturais presentes em floresta próxima à região e de outros projetos de arborização do próprio município. A introdução de plantas da proximidade via plantios de mudas para a arborização é o principal fator responsável pela estruturação das populações estudadas, pois as plantas são representativas de cada área de estudo e representa uma amostragem da diversidade genética das plantas presentes em cada região.

Tabela 4. Distribuição da variação genética entre e dentro de populações de Cenostigma tocantinum.

Table 4. Distribution of genetic variation among and within populations of Cenostigma tocantinum.

\begin{tabular}{lccc}
\hline Fonte de Variação & Grau de Liberdade & Componente de Variância & \% da Variação \\
\hline Entre populações: $\Phi_{s t}$ & 2 & $11,3042^{* *}$ & 36,6 \\
Dentro de populações & 87 & $19,5644^{* *}$ & 63,4 \\
\hline
\end{tabular}

*** $P<0,01$.

Para a conservação, deve-se levar em consideração o padrão de variabilidade genética encontrado em C. tocantinum, sendo necessária uma amostragem representativa do conjunto de genes contidos em cada população, com a amostragem de indivíduos em todas as populações, uma vez que a maior diversidade é intrapopulacional. A conservação genética deve priorizar a conservação participativa in situ nas áreas de ocorrência das populações, visto que tal estratégia vai conservar outras espécies de plantas e animais.

\section{CONCLUSÕES}

Os marcadores moleculares do tipo AFLP revelaram alto conteúdo de informação genética em $C$. tocantinum e podem ser utilizados para análises genéticas, visando obter informações para a sustentabilidade genética e o manejo florestal da espécie.

A introdução de plantas em novos projetos, oriundas de amostragem adequada em outras populações, auxilia na conservação genética da espécie.

A distribuição da diversidade genética nas populações estudadas de C. tocantinum é maior dentro do que entre as populações, sendo necessária a conservação de vários indivíduos por população, a fim de se preservar a alta diversidade genética encontrada. 
Almeida et al. - Diversidade genética entre e dentro

de populações de Cenostigma tocantinum Ducke

\section{REFERÊNCIAS BIBLIOGRÁFICAS}

AGUIAR, R. V.; CANSIAN, R. L.; KUBIAK, G. B.; SLAVIERO, L. B.; TOMAZONI, T. A.; BUDKE, J. C.; MOSSI, A. J. Variabilidade genética de Eugenia uniflora L. em remanescentes florestais em diferentes estádios sucessionais. Revista Ceres, Viçosa, v. 60, n. 2, p. 226-233, 2013.

BATISTA, C. M.; FREITAS, M. L. M.; MORAES, M. A. D.; ZANATTO, A. C. S.; SANTOS, P. C. D.; ZANATA, M.; MORAES, M. L. T. D.; SEBBENN, A. M. Estimativas de parâmetros genéticos e a variabilidade em procedências e progênies de Handroanthus vellosoi. Pesquisa Florestal Brasileira, Colombo, v. 32, n. 71, p. 269-276, 2012.

BONIN, A.; EHRICH, D.; MANEL, S. Statistical analysis of amplified fragment length polymorphism data: a toolbox for molecular ecologists and evolutionists. Molecular Ecology, Oxford, v. 16, n. 18, p. 3737-3758, 2007.

BOSSART, J. L.; PROWELL, D. P. Genetic estimates of population structure and gene flow: limitations, lessons and new directions. Trends in Ecology \& Evolution, London, v. 13, n. 5, p. 202-206, 1998.

CRESTE, S.; TULMANN NETO, A.; FIGUEIRA, A. Detection of single sequence repeat polymorfisms in denaturing polyacrylamide sequencing gels by silver staining. Plant Molecular Biology Reporter, New York, v. 19, n. 4, p. 299-306, 2001.

EARL, D. A.; VONHOLDT, B. M. STRUCTURE HARVESTER: a website and program for visualizing STRUCTURE output and implementing the Evanno method. Conservation Genetics Resources, Netherlands, v. 4, n. 2, p. 359-361, 2011.

ESTOPA, R. A.; SOUZA, A. M.; MOURA, M. C. O.; BOTREL, M. G. G.; MENDONÇA, E. G.; CARVALHO, D. Diversidade genética em populações naturais de candeia (Eremanthus erythropappus (DC.) MacLeish). Scientia Forestalis, Piracicaba, n. 70, p. 97-106, 2006.

EVANNO, G.; REGNAUT, S.; GOUDET, J. Detecting the number of clusters of individuals using the software STRUCTURE: a simulation study. Molecular Ecology, Oxford, v. 14, n. 8, p. 2611-2620, 2005.

FALUSH, D.; STEPHENS, M.; PRITCHARD, J. K. Inference of population structure using multilocus genotype data: linked loci and correlated allele frequencies. Genetics, Austin, v. 164, n. 4, p. 1567-1587, 2003.

FERREIRA, M. E.; GRATTAPAGLIA, D. Introdução ao uso de marcadores moleculares em análise genética. Brasília: EMBRAPA-CENARGEN, 1998. 220 p.

GARCIA, L. C.; MORAES, R. P. D.; LIMA, R. M. B. D. Determinação do grau crítico de umidade em sementes de Cenostigma tocantinum Ducke. Revista Brasileira de Sementes, Londrina, v. 30, n. 3, p. 172-176, 2008.

GOMES, L. R. P.; LOPES, M. T. G.; BENTES, J. L. D. S.; BARROS, W. S.; NETO, C.; DE QUEIROZ, P.; CONTIM, L. A. S. Genetic diversity in natural populations of Buriti (Mauritia flexuosa L. f.). Crop Breeding and Applied Biotechnology, Viçosa, v. 11, n. 3, p. 216-223, 2011.

LINS, P. M. P.; FARIAS NETO, J. T.; MULLER, A. A. Avaliação de híbridos de coqueiro (Cocos nucifera L.) para produção de frutos e de albúmen sólido fresco. Revista Brasileira de Fruticultura, Jaboticabal, v. 25, n. 3, p. 468-470, 2003.

LOPES, R.; LOPES, M. T. G.; FIGUEIRA, A. V. D. O.; CAMARGO, L. E. A.; FUNGARO, M. H. P.; CARNEIRO, M. S.; VIEIRA, M. L. C. Marcadores moleculares dominantes (RAPD e AFLP): Aspectos técnicos e interpretação genética. Biotecnologia Ciência e Desenvolvimento, Brasília, v. 29, p. 64-68, 2003. 
MAGAlHÃES, M. A.; LOPES, M. T. G.; COElHO, L. M.; NETO, P. D. Q. C.; BENTES, J. L. D. S. Genetic diversity within and among populations of Cajazeira. Revista de Ciências Agrárias/Amazonian Journal of Agricultural and Environmental Sciences, Belém, v. 56, n. Supl., p. 61-67, 2013.

MANTEL, N. The detection of disease clustering and a generalized regression approach. Cancer research, Philadelphia, v. 27, n. 2, Part 1, p. 209-220, 1967.

NEI, M. Estimation of average heterozygosity and genetic distance from a small number of individuals. Genetics, Austin, v. 89, n. 3, p. 583-590, 1978.

OKSANEN, J.; BLANCHET, F. G.; KINDT, R.; OKSANEN, M. J.; SUGGESTS, M. Vegan: Community Ecology Package: R package 2.0-10, 2013.

PEAKALL, R.; SMOUSE, P. E. GenAlEx 6.5: genetic analysis in Excel. Population genetic software for teaching and research - an update. Bioinformatics, Oxford, v. 28, n. 19, p. 2537-2539, 2012.

PRITCHARD, J. K.; STEPHENS, M.; DONNELLY, P. Inference of population structure using multilocus genotype data. Genetics, Austin, v. 155, n. 2, p. 945-959, 2000.

R DEVELOPMENT CORE TEAM. R: A language and environment for statistical computing. Vienna: R Foundation for Statistical Computing, 2013. Disponível em: < http://www.r-project.org >. Acesso em: 02 jan 2015.

ROSENBERG, N. A. Distruct: a program for the graphical display of population structure. Molecular Ecology Notes, Oxford, v. 4, n. 1, p. 137-138, 2003.

ROSSI, F. S.; ROSSI, A. A. B.; DARDENGO, J. F. E.; BRAUWERS, L. R.; SILVA, M. L.; SEBBENN, A. M. Diversidade genética em populações naturais de Mauritia flexuosa L. f. (Arecaceae) com uso de marcadores ISSR. Scientia Forestalis, Piracicaba, v. 42, n. 104, p. 631-639, 2014.

SHANNON, C. E.; WEAVER, W. A. Mathematical model of communication. Urbana: University of Illinois Press, 1949.

SILVA, R. L. Fenologia em ambiente urbano, morfologia da semente e da plântula e germinação sob condições adversas de Cenostigma tocantinum Ducke. 2007. 64 p. Dissertação (Mestrado em Ciências Agrárias) - Instituto Nacional de Pesquisas da Amazônia e Universidade Federal do Amazonas, Manaus, 2007.

SLATKIN, M.; BARTON, N. H. A comparison of three indirect methods for estimating average levels of gene flow. Evolution, Lancaster, v. 43, n. 7, p. 1349-1368, 1989.

SOKAL, R. R.; ROHLF, F. J. The comparison of dendrograms by objective methods. Taxon, Netherlands, v. 11, n. 2, p. 33-40, 1962.

SYSTMA, K. J.; GIVNISH, T. J.; SMITH, J. F.; HAHN, W. J. Collection and storage of land plant samples for macromolecular comparisons. Methods in enzymology, New York, v. 224, p. 23-37, 1993.

TOREZAN, J. M. D.; SOUZA, R. F.; RUAS, P. M.; RUAS, C. F.; CAMARGO, E. H.; VANZELA, A. L. L. Genetic variability of pre and post-fragmentation cohorts of Aspidosperma polyneuron Muell. Arg. (Apocynaceae). Brazilian Archives of Biology and Technology, Curitiba, v. 48, n. 2, p. 171-180, 2005.

VIANA, J. M. S.; VALENTE, M. S. F.; SILVA, F. F.; MUNDIM, G. B.; PAES, G. P. Efficacy of population structure analysis with breeding populations and inbred lines. Genetica, s'-Gravenhage, v. 141, n. 7-9, p. 389-399, 2013. 
Almeida et al. - Diversidade genética entre e dentro

de populações de Cenostigma tocantinum Ducke

VOS, P.; HOGERS, R.; BLEEKER, M.; REIJANS, M.; LEE, T. V. D.; HORNES, M.; FRITERS, A.; POT, J.; PALEMAN, J.; KUIPER, M.; ZABEAU, M. AFLP: a new technique for DNA fingerprinting. Nucleic acids research, Oxford, v. 23, n. 21, p. 4407-4414, 1995.

VUYLSTEKE, M.; PELEMAN, J. D.; VAN EIJK, M. J. AFLP technology for DNA fingerprinting. Nature protocols, London, v. 2, n. 6, p. 1387-1398, 2007.

WARWICK, M.; LEWIS, G. A revision of Cenostigma (Leguminosae-Caesalpinioideae-Caesalpinieae), a genus endemic to Brazil. Kew Bulletin, London, v. 64, n. 1, p. 135-146, 2009.

YEH, F. C.; YANG, R. C.; BOYLE, T. Popgene version 1.32. Microsoft windows - based freeware for population genetic analysis. Edmonton: University of Alberta, 1999. 300 p.

Recebido em 01/12/2014

Aceito para publicação em 19/05/2015 